This item was submitted to Loughborough's Research Repository by the author.

Items in Figshare are protected by copyright, with all rights reserved, unless otherwise indicated.

\title{
An experimental investigation of human mismatches in machining.
}

PLEASE CITE THE PUBLISHED VERSION

PUBLISHER

Professional Engineering Publishing (@ IMechE)

VERSION

VoR (Version of Record)

LICENCE

CC BY-NC-ND 4.0

\section{REPOSITORY RECORD}

Case, Keith, Murray A. Sinclair, and A.M. Abdul-Rani. 2019. "An Experimental Investigation of Human Mismatches in Machining.”. figshare. https://hdl.handle.net/2134/4422. 
This item was submitted to Loughborough's Institutional Repository (https://dspace.lboro.ac.uk/) by the author and is made available under the following Creative Commons Licence conditions.

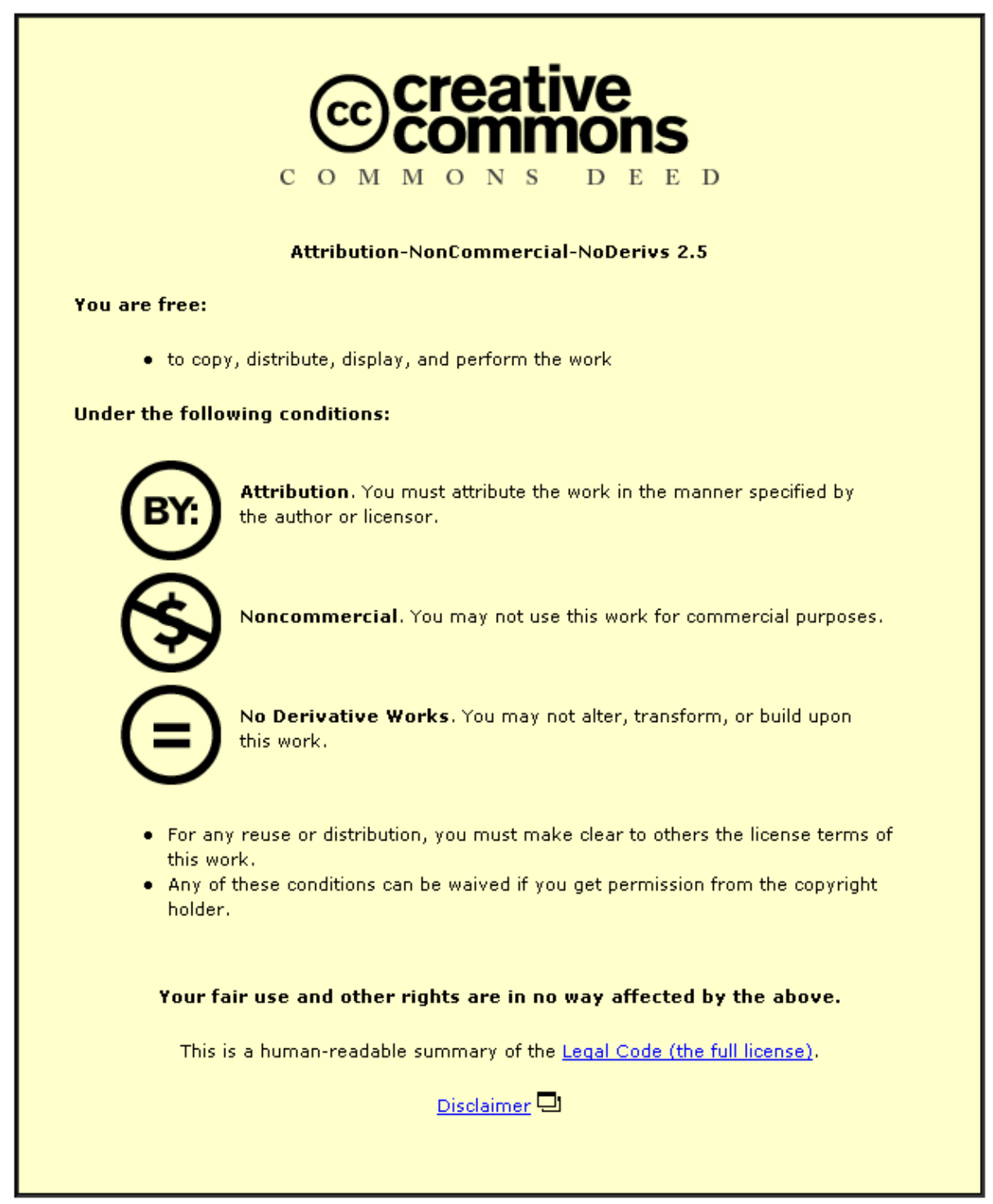

For the full text of this licence, please go to: http://creativecommons.org/licenses/by-nc-nd/2.5/ 


\title{
An experimental investigation of human mismatches in machining
}

\author{
K Case ${ }^{1 *}$, M A Sinclair ${ }^{2}$ and M R Abdul Rani ${ }^{3}$ \\ ${ }^{1}$ Department of Manufacturing Engineering, Loughborough University, Leicestershire, UK \\ ${ }^{2}$ Department of Human Sciences, Loughborough University, Leicestershire, UK \\ ${ }^{3}$ Faculty of Mechanical Engineering, Universiti Teknologi Malaysia, Malaysia
}

\begin{abstract}
Mismatches refer to incompatibilities, inappropriateness, unsuitabilities or inconsistencies in machine operators' actions which, if not addressed, would lead to errors. A fuller understanding of the rate at which mismatches occur and their causes would allow human aspects to be given proper consideration alongside hardware and technological issues in the design of new working environments, machines and tasks. This research highlights these human aspects of machining by examining mismatches in relation to various human characteristics.

The human task-mismatch matching method was developed and applied in manual turning operations using experimental and questionnaire techniques on groups of 16 skilled and 12 unskilled operators. The skilled subjects were drawn from local industry and university technical staff. Unskilled subjects were engineering students, all of whom had some familiarity with machining through periods of industrial placement. Statistically significant relationships were established between mismatches and many of the human characteristics studied (skill, age, work experience, self-confidence and trust) when considering all the subjects as a single group, but for skilled operators alone, the only significant relationship was between self-confidence and trust.

As a general conclusion, it can be confirmed that studying operators in their own workplace provides invaluable information for the design and operation of future workplaces, but that the relationships between performance and human characteristics remain difficult to establish formally.
\end{abstract}

Keywords: human factors, mismatches, machining

\section{INTRODUCTION}

It is widely accepted that consideration of the human operators of manufacturing equipment, whether it be highly automated or manual, is essential for high levels of performance of the human-machine system [1]. This can be expressed as a requirement to allocate functions between humans and machines, or more appropriately to devise an appropriate sharing of functions that produces a satisfactory overall system performance. In either case it is necessary to have an understanding of human performance capabilities in just the same way as technological constraints must be recognized. Although much work has been carried out on these human aspects, there remain many areas where knowledge is

The MS was received on 18 November 1998 and was accepted for publication on 20 November 1998.

*Corresponding author: Department of Manufacturing Engineering, Loughborough University, Loughborough, Leicestershire LE11 3TU, UK.

SC0398 @ IMechE 1999 limited and imprecise. One such area is that of mismatches between expected and delivered human performance in a manufacturing context, and the development of suitable research methodologies to address this inadequacy is the overall objective of the research described here.

Mismatches refer to incompatibilities, inappropriateness, unsuitabilities or inconsistencies [2], and are considered here with an emphasis on turning operations. Human characteristics may influence the occurrence of mismatches and hence a deeper understanding is useful to reinforce and extend existing knowledge, especially of the requirements of the human-machine interface. Hence human factor issues in machining tasks have been studied by examining the problems of mismatches and their relationships with various human characteristics, including age, skill, work experience, self-confidence and trust.

An understanding of the elements of expertise provides the principles for more effective training of 
machinists and the design of machine tools with humancentred features properly based on human psychological, technical and physical characteristics. The specific objective then was to establish relationships between (a) mismatches and skill, self-confidence, level of trust, work experience and age, (b) self-confidence and skill, level of trust, work experience and age and (c) level of trust and skill, work experience and age.

Most operator errors arise from a mismatch between the properties of the system as a whole and the characteristics of human information processing [3], and thus mismatches between operators and equipment need to be identified by task. Research into trust and self-confidence of operators on machine systems has been focused on automated systems [4-6], but an understanding of trustworthiness and self-confidence on manually-operated machines provides the basis for development of those characteristics on automated systems.

\section{MISMATCHES}

The problems of mismatches in machining operations are centred on people, and the actions of individual operators result in matches or mismatches between tasks and actions. In this research inappropriate, incompatible, unsuitable or inconsistent actions are considered mismatches and consist of:

\begin{tabular}{|c|c|}
\hline Intrusion & Help required in proceeding \\
\hline Omission & A step omitted from the task \\
\hline Commission & A step performed incorrectly \\
\hline Reversal & $\begin{array}{l}\text { Steps repeated due to an } \\
\text { earlier omission }\end{array}$ \\
\hline Wrong request & For tools, etc. \\
\hline Wrong components & $\begin{array}{l}\text { Operating on incorrect } \\
\text { components }\end{array}$ \\
\hline Repetition & $\begin{array}{l}\text { A step is unnecessarily } \\
\text { repeated }\end{array}$ \\
\hline Misapplication & $\begin{array}{l}\text { Incorrect execution of a } \\
\text { method }\end{array}$ \\
\hline Violations & $\begin{array}{l}\text { Standard procedures } \\
\text { contravened }\end{array}$ \\
\hline
\end{tabular}

Clearly these mismatches are closely related to errors. However, mismatches are distinguished from errors in that mismatches, while being a likely source of errors, need not become identifiable errors if recognized and avoided. Mismatches are considered to be a more subtle and direct measure of human performance than simply recording output errors.

\section{THE HYPOTHESES}

An extensive review [7] of literature on human problems in machining operations led to the development of the following twelve hypotheses:

Mismatches:

H1 More skilled operators commit fewer mismatches.

H2 Operators having high self-confidence commit fewer mismatches.

H3 Operators having a high level of trust commit fewer mismatches.

H4 Operators with greater experience commit fewer mismatches.

H5 Older operators commit fewer mismatches.

Self-confidence:

H6 More skilled operators have higher self-confidence.

H7 The higher the self-confidence, the higher the level of trust.

H8 Operators with greater experience have more self-confidence.

H9 Older operators have more selfconfidence.

Level of trust:

H10 More skilled operators have more trust.

H11 Operators with greater experience have more trust.

H12 Older operators have more trust.

Figure 1 depicts the relationships between the variables of these hypotheses.

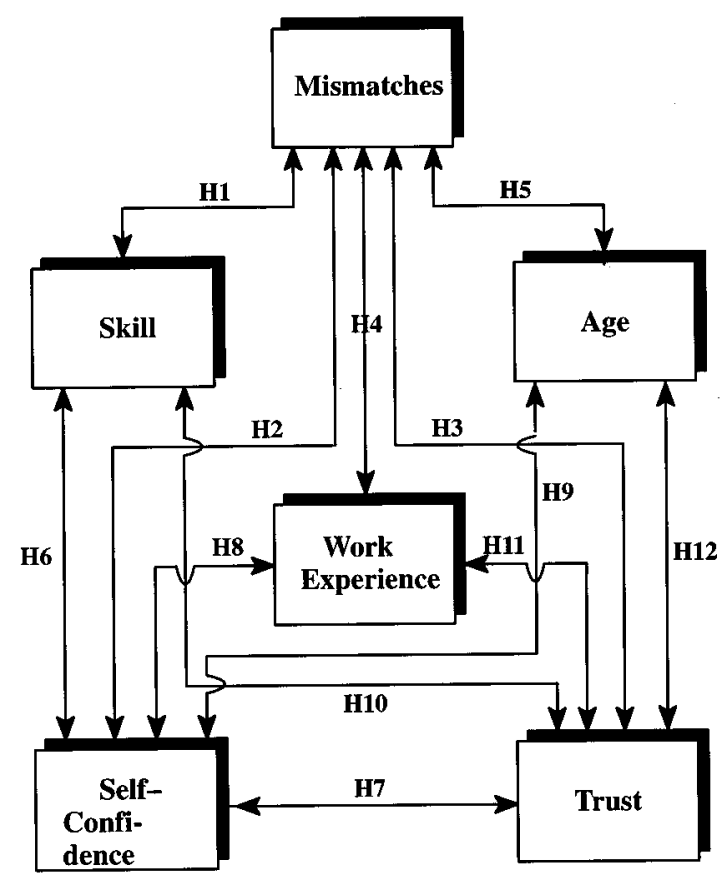

Fig. 1 A model of hypotheses depicting the relationships between variables 


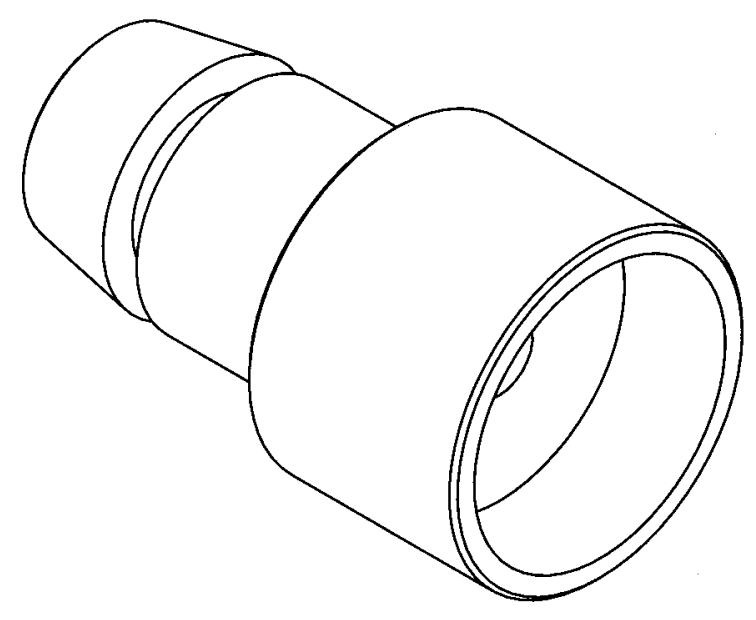

Fig. 2 The component used in the experimental study

\section{THE HUMAN TASK-MISMATCH MATCHING METHOD}

The human task-mismatch matching (HTMM) method was developed to establish the relationships between human characteristics and mismatches and resembles the task difficulty and criticality rating (TDCR) method [8]. The HTMM method takes its name from the way in which each subtask is matched to the possible mismatches. Mismatches are quantified based on the performance of task elements in machining operations, and the total compared to the ideal performance. The method uses both simulated field study and questionnaire survey techniques to generate reliable and valid results.

In the simulated field study operators were observed as they used familiar machines in their own workplace to machine a simple standard part (Fig. 2) with some freedom in the operational methods employed. Questionnaire studies were also used to evaluate the performance of operators in machining tasks based on their own experience, expert opinions and daily encounters at the workplace. The questionnaires were administered both before and after the machining experiment in the form of a structured interview with the subjects taking part in the experimental studies.

\section{ANALYSIS AND INTERPRETATION OF RESULTS}

Analysis of the data was carried out using statistical methods including Mann-Whitney U, chi-square, Wilcoxon matched-pairs signed ranks tests and Spearman correlation coefficients. Objective performance data were obtained from the total number and categories of mismatches committed by subjects during the machining trials. Subjective data were collected from the questionnaire survey using psychophysical ranking (1-10) for self-confidence and trust.

The occurrence of mismatches (Table 1) shows that 'repetition' predominates for skilled operators and 'requiring assistance' predominates for unskilled operators.

\subsection{Mismatches}

Hypothesis $\mathrm{H} 1$ related the rate of mismatches to the level of skill. Skill is a product of extensive training, long-term exposure to manufacturing processes and frequent execution of similar machining tasks. Repetition constituted 72 per cent of mismatches committed by skilled operators, and these resulted from mechanical failures including mechanical engagement (e.g. selecting speed by engaging levers), parts assembly (e.g. setting up tools on tool posts) and problems in manual aspects of machining processes (e.g. tool selection). The repetition mismatch is considered significant in the sense that the design and handling of mechanical parts requires improvements in terms of design, accuracy and the consideration of user aspects for better handling in set-up and selection functions. Unskilled operators committed more mismatches, which can be attributed to lower anticipation which is known to be important for skilled performance [9]. Lower anticipation results from inadequate training and a detailed study of the results should be useful in establishing training requirements.

A significant relationship between mismatches and self-confidence (hypothesis H2) was found for both skill categories: the greater the self-confidence, the fewer the mismatches. Unlike unskilled operators, skilled operators have high self-confidence due to their skill and training, and this allows them to commit fewer mismatches. Understanding the relationship between mismatches and self-confidence should be useful in the development of training programmes and machine or system design.

Table 1 Occurrence of mismatches for skilled $(n=16)$ and unskilled $(n=12)$ operators

\begin{tabular}{lcc}
\hline Mismatches & Skilled operators & Unskilled operators \\
\hline 1. Intrusion & 5 & 306 \\
2. Omission & 6 & 27 \\
3. Commission & 4 & 37 \\
4. Reversal in sequence & 8 & 7 \\
5. Wrong request & 1 & 3 \\
6. Repetition & 112 & 83 \\
7. Wrong components & 12 & 27 \\
8. Misapplication & 0 & 13 \\
9. Violations & 8 & 25 \\
10. Other causes & 0 & 0 \\
Total & 156 & 528 \\
\hline
\end{tabular}


A relationship was found between the occurrence of mismatches and trust (hypothesis H3): the greater the trust, the fewer the mismatches. This corresponds to previous findings [4] where it was suggested that system performance and occurrence of faults could affect trust. Trust can be developed through experience, training and familiarization. This indicates the importance of careful planning of technology acquisition and of attention to human resource programmes. Other parameters such as sociological aspects may also be significant and worthy of investigation in this context.

Hypothesis $\mathrm{H} 4$ is confirmed in that operators with longer work experience commit fewer mismatches. This finding formally establishes an important characteristic of skilled operators, but the challenge remains to achieve low mismatches with short working experience.

The study established that older operators commit fewer mismatches (hypothesis H5), contradicting earlier opinions [10]. Age is normally synonymous with maturity, which is a factor in human capability. However, the findings here are limited to the working age group (20-55 years). The conclusion to be drawn from this is that machine design should include an analysis of the controls and job aids that would benefit younger operators.

\subsection{Self-confidence}

Skill has been shown to be related to self-confidence (hypothesis H6). Skillfulness may instil high self-confidence among machine operators, and thus it is necessary to maintain skillfulness simply for the sake of maintaining self-confidence. Skillfulness could be maintained by refresher courses and a reduced level of automation to ensure mental stimulation [11].

It has been suggested that mistrust would cause inappropriate task allocation strategies and influence operators' reliance [4]. Therefore, operators' trust on machines needs to develop in parallel with their selfconfidence. The analysis confirmed hypothesis $\mathrm{H} 7$ that operators having higher levels of self-confidence have correspondingly high levels of trust in machines.

The informal view that working experience instils self-confidence is confirmed by the study (hypothesis H8), and agrees with reference [12] that self-efficacy would cause, and might be caused by, performance experiences. However, the extremes of the characteristic, lack of self-confidence and overconfidence for skilled or unskilled operators, are detrimental to the execution of tasks.

Age and self-confidence were found to be related (hypothesis H9), which is in keeping with the earlier finding (the relationship between mismatches and age) and emphasizes the fact that age is an important con- tributor towards the design of tasks and machine designs. Learning and experience increase with age and instil self-confidence, particularly for psychomotor skills.

\subsection{Trust}

Trust has always been associated with self-confidence [4]. Positive relationships were found between trust and skill (hypothesis H10) but no significant relationships were found with experience (H11) and age (H12). This concurs with the previous finding that high trust corresponds to fewer mismatches, and also supports the suggestion that trust helps to reduce complexity and uncertainty [13]. This should be exploited in manufacturing where machine designs need to cater for all types of operators. Training should be designed to enable operators, especially new and unskilled operators, to gain an adequate level of trust. The absence of relationships between trust and work experience and trust and age suggest that trust does not naturally occur in older and more experienced workers, so retraining is justified if only to reinforce the level of trust.

\section{CONCLUSIONS}

Human needs, skill, creativity and potential should be the focus of human-centred technological systems, and this calls for a critical analysis of human performance, including mismatches. This research has provided a part of this analysis and extended understanding of some important human characteristics as they relate to machining tasks. It is envisaged that this knowledge will be useful in designing better manual systems while at the same time providing insights into the human needs of automated systems.

\section{REFERENCES}

1 Sanders, M. S. and McCormick, E. J. Human Factors in Engineering and Design, International Editions, Industrial Engineering Series, 6th edition, 1987 (McGraw-Hill, New York).

2 Urdang, L. The Oxford Thesaurus, 1991 (Oxford University Press).

3 Reason, J. Cognitive aids in process environments: prostheses or tools? Int. J. of Man-Machine Studies, 1987, 27, $463-470$.

4 Lee, J. D. and Moray, N. Trust, self-confidence and operators' adaptation to automation. Int. J. of HumanComputer Studies, 1994, 1, 153-184.

5 Muir, B. M. Trust in automation: Part I. Theoretical issues in the study and human intervention in automated systems. Ergonomics, 1994, 37(11), 1905-1922. 
6 Muir, B. M. and Moray, N. Trust in automation. Part II. Experimental studies of trust and human intervention in a process control simulation. Ergonomics, 1996, 39(3), 429460.

7 Abdul Rani, M. R. Human mismatches in machining. PhD thesis, Loughborough University, 1997.

8 Williams, J. C. Human factors analysis of automation requirements - a methodology for allocating functions. In 10th Advances in Reliability Technology Symposium (Ed. G.P. Libberton), 1988 (Elsevier Applied Science, London).

9 Holding, D. H. Skill research. In Human Skills (Ed. D.H. Holding), 1981 (John Wiley, Chichester).
10 Welford, A. T. Ageing and Human Skill, 1958 (The Nuffield Foundation, Oxford University Press).

11 Ekkers, C. L., Pasmooij, C. K., Brouwers, A. A. F. and Janusch, A. J. Human control tasks: a comparative study in different man-machine systems. In Proceedings of the IFAC Workshop, Enschede, Netherlands, 1979 (Pergamon Press, Oxford).

12 Silver, W., Mitchell, T. R. and Bist, M. E. Responses to successful and unsuccessful performances: the moderating effect of self-efficacy on the relationship between performance and attributions. Organisational Behaviour and $\mathrm{Hu}$ man Decision Process, 1995, 62(3), 286-299.

13 Luhman, N. Trust and Power, 1980 (John Wiley, New York). 